\title{
Mathematical modeling and analysis of spinal circuits involved in locomotor pattern generation and frequency-dependent left-right coordination
}

\author{
Yaroslav I Molkov*, Bartholomew J Bacak², Ilya A Rybak² \\ From The Twenty Third Annual Computational Neuroscience Meeting: CNS*2014 \\ Québec City, Canada. 26-31 July 2014
}

Coordination between left and right neural activities in the spinal cord during locomotion is controlled by commissural interneurons (CINs). Several CIN types have been genetically identified, including the excitatory V3 and excitatory and inhibitory V0 types. Talpalar et al. [1] recently reported that genetic elimination of the V0 CINs caused switching from a normal left-right alternating pattern of motor activity to a left-right synchronized "hopping" pattern. Furthermore, ablation of only the inhibitory V0 neurons ( $\mathrm{VO}_{\mathrm{D}}$ subtype) resulted in a lack of left-right alternation at low locomotor frequencies and maintaining this alternation at high frequencies, whereas selective ablation of the excitatory V0 neurons $\left(\mathrm{V}_{\mathrm{V}}\right.$ subtype) maintained the left-right alternation at low locomotor frequencies and switched the motor output to a left-right synchronized ("hopping") pattern at high frequencies.

To analyze and explain the above findings, we developed a simplified mathematical model of neural circuits consisted of four pacemaker neurons representing left (LF) and right (RF) flexor and left (LE) and right (RE) extensor half-centers interacting via commissural pathways representing $\mathrm{V} 3, \mathrm{VO}_{\mathrm{D}}$, and $\mathrm{VO}_{\mathrm{V}} \mathrm{CINs}$ (Fig. 1). The "locomotor" frequency in the model was controlled by a parameter defining the excitability of neurons (via the leak reversal potentials) and commissural pathways, whose changes represented the corresponding changes induced by changing the concentration of N-methyl-D-aspartate (NMDA) applied to control the locomotor frequency in the isolated rodent spinal cord preparations [1].

\footnotetext{
* Correspondence: ymolkov@iupui.edu

'Department of Mathematical Sciences, Indiana University - Purdue

University Indianapolis, IN 46202, USA

Full list of author information is available at the end of the article
}

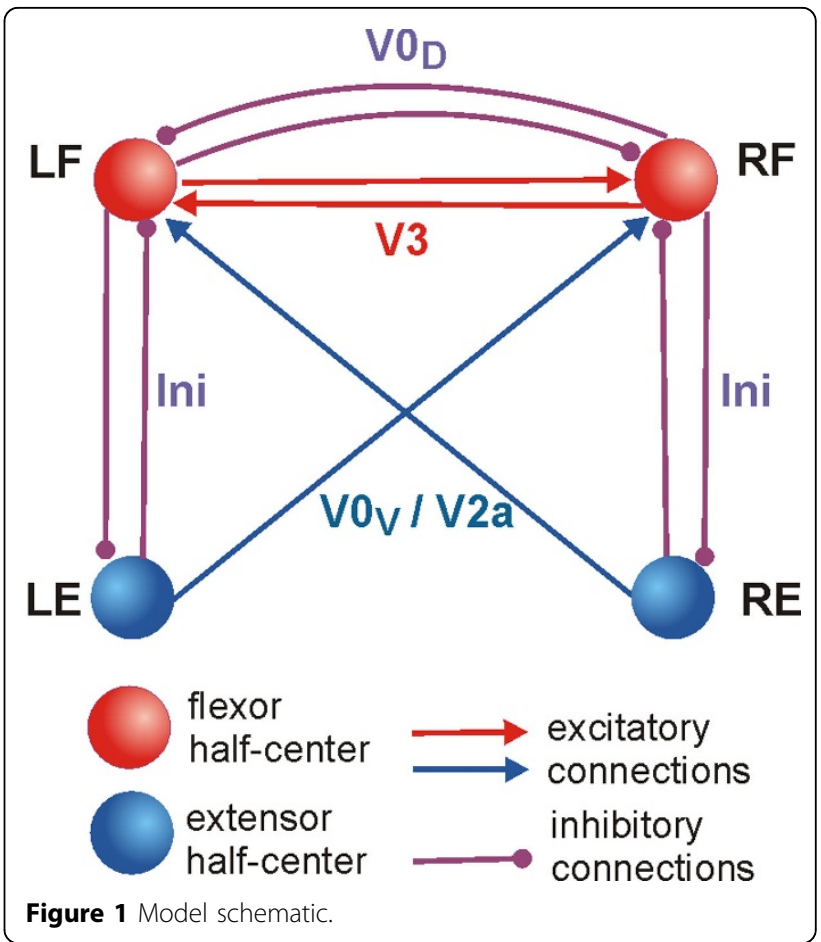

The model demonstrated: (1) a typical left-right alternating pattern under control conditions; (2) switching to a synchronized hopping activity at any frequency after removing commissural connections representing both $\mathrm{V} 0\left(\mathrm{VO}_{\mathrm{D}}\right.$ and $\left.\mathrm{V} 0_{\mathrm{V}}\right)$ neurons; (3) a synchronized left-right pattern at low frequencies and left-right alternation of activity at high frequencies after removing the commissural connections representing $\mathrm{V}_{\mathrm{D}}$ neurons; (4) an alternating left-right pattern at low frequencies with synchronized hopping at high frequencies after removing the commissural connections representing $\mathrm{V}_{\mathrm{V}}$ neurons. 
We used the bifurcation and fast-slow decomposition methods to analyze the behavior of this network in the four above states/regimes and transitions between them. The model was able to reproduce and provide explanation to several important experimental phenomena and generated predictions that can be tested experimentally.

\section{Acknowledgements}

Supported by NIH grant R01NS7323.

\section{Authors' details}

'Department of Mathematical Sciences, Indiana University - Purdue

University Indianapolis, IN 46202, USA. ²Department of Neurobiology and

Anatomy, Drexel University College of Medicine, Philadelphia, PA 19129,

USA.

Published: 21 July 2014

\section{Reference}

1. Talpalar AE, Bouvier J, Borgius L, Fortin G, Pierani A, Kiehn O: Dual-mode operation of neuronal networks involved in left-right alternation. Nature 2013, 500(7460):85-93.

doi:10.1186/1471-2202-15-S1-P53

Cite this article as: Molkov et al:: Mathematical modeling and analysis

of spinal circuits involved in locomotor pattern generation and

frequency-dependent left-right coordination. BMC Neuroscience 2014

15(Suppl 1):P53.

\section{Submit your next manuscript to BioMed Central} and take full advantage of:

- Convenient online submission

- Thorough peer review

- No space constraints or color figure charges

- Immediate publication on acceptance

- Inclusion in PubMed, CAS, Scopus and Google Scholar

- Research which is freely available for redistribution

Submit your manuscript at www.biomedcentral.com/submit 